\title{
Substrate-Reduction Therapy Enhances the Benefits of Bone Marrow Transplantation in Young Mice with Globoid Cell Leukodystrophy
}

\author{
SANGITA BISWAS AND STEVEN M. LEVINE \\ Department of Molecular and Integrative Physiology and the Mental Retardation and Human \\ Development Research Center, University of Kansas Medical Center, Kansas City, Kansas 66160, U.S.A. \\ [S.B., S.M.L.]
}

\begin{abstract}
ABST
Globoid cell leukodystrophy is an autosomal recessive dis-
ease with progressive demyelination caused by a deficiency of
the lysosomal enzyme galactosylceramidase. Bone marrow trans-
plantation (BMT) is a therapeutic option for patients with late-
onset disease and for patients with early onset disease that had an
early diagnosis owing to an affected sibling. This therapy, how-
ever, typically is not effective for early onset disease when the
diagnosis occurs after several months of life. In an effort to
enable a broader range of patients to benefit from BMT, we
tested whether combining substrate-reduction therapy with BMT
would result in a greater benefit than either treatment alone in the
twitcher mouse model of globoid cell leukodystrophy. Twitcher
mice treated with L-cycloserine, an inhibitor of 3 -ketodyhy-
drosphingosine synthase, and transplanted with $50 \pm 5 \times 10^{6}$
bone marrow cells on d 10 had a mean life-span of $112 \mathrm{~d}$
compared with $51 \mathrm{~d}$ for BMT alone ( $p<0.001)$ or L-cycloserine
alone, which was previously reported to be $56 \mathrm{~d}$. L-Cycloserine
\end{abstract}
treatment also was initiated neonatally to determine whether it would allow for a delayed BMT to have therapeutic value. Twitcher mice given only BMT at $18 \mathrm{~d}$ or only a short course of L-cycloserine died at 36 and $37 \mathrm{~d}$, respectively. Twitcher mice given a short course of L-cycloserine + BMT at $18 \mathrm{~d}$ lived to $58 \mathrm{~d}$ $(p=0.0006)$. In conclusion, substrate-reduction therapy enhanced the value of BMT in twitcher mice, suggesting that this combination strategy might benefit patients with globoid cell leukodystrophy. (Pediatr Res 51: 40-47, 2002)
Abbreviations
BMT, bone marrow transplantation
GCL, globoid cell leukodystrophy
GFAP, glial fibrillary acidic protein
HBSS, Hanks' balanced salt solution
MBP, myelin basic protein

GCL is an autosomal recessive disease that is caused by a mutation in the gene encoding the lysosomal enzyme galactosylceramidase (1). This enzyme digests galactosylceramide, a major glycolipid of central and peripheral myelin, and psychosine, a secondary byproduct of UDP-galactosylceramide transferase, which also synthesizes galactosylceramide. The development of pathology has been proposed to be caused by the accumulation of psychosine (2), as it has been shown to be toxic to a variety of cells (3-5) and its concentration increases dramatically in this disease (6). Pathologically, GCL is characterized by extensive demyelination throughout the white matter of the CNS, astrocytosis, and the appearance of globoid cells (7-9), which are multinucleated cells derived from the

Received May 28, 2001; accepted September 12, 2001.

Correspondence and reprint requests: Steven M. LeVine, Ph.D., Department of Molecular and Integrative Physiology, University of Kansas Medical Center, 3901 Rainbow Boulevard, Kansas City, KS 66160, U.S.A.; e-mail: slevine@kumc.edu

Supported by grants from the Hunter's Hope Foundation (799 MS), National Institute of Neurological Disorders and Stroke (NS 36544), and National Institute of Child Health and Human Development Mental Retardation Center (HD 02528). monocyte-macrophage linage and are thought to contain undigested psychosine and galactosylceramide.

Several forms of GCL have been identified in humans based on the age of the symptoms: early infantile (3-6 mo), late infantile ( $3 \mathrm{mo}-3 \mathrm{y})$, juvenile $(3-10 \mathrm{y})$, and adult forms $(>10$ $y)$ of the disease $(10,11)$. The most common clinical features of early onset disease are hypersensitivity to external stimuli, ataxia, tremor, progressive mental and motor deterioration, spasticity, blindness, deafness, and wasting leading to death. In the late-onset disease, the initial presentation is relatively less severe, which is combined with a slower disease course. BMT is a promising therapeutic approach for the presymptomatic child or late-onset patient (12-14). Both sets of patients may have residual enzyme activity, which is thought to lead to a slower disease course $(11,13,15)$. Successfully engrafted patients have an improved life expectancy, stabilization or improvement in neurologic tests, and some evidence of remyelination $(13,16)$. Because the rate of entry of donor-derived cells into the CNS occurs slowly over an extended period after engraftment $(17,18)$, the balance between enzymatic replace- 
ment owing to engraftment and ongoing destruction owing to disease is more favorable in the late-onset form (19). Treatment of the infantile form of GCL still presents a significant challenge because deterioration occurs rapidly, and in most cases the diagnosis occurs at an advanced stage in the disease course when current transplantation protocols cannot substantially alter disease progression. Intervention strategies, which slow the disease course, may allow transplantation to have greater therapeutic value in the early infantile disease.

The twitcher mouse has a naturally occurring mutation in its galactosylceramidase gene (20), and its clinical, biochemical, and pathologic profiles resemble those present in human infantile GCL (20-22). For example, twitcher mice appear normal at birth and develop tremor at $3 \mathrm{wk}$, which rapidly progresses to severe resting tremor, weight loss, paralysis and wasting of hind legs, weakness of facial muscles, and death around 35-40 d (23).

The twitcher mouse has been used extensively for enzymereplacement therapy by BMT $(18,24-26)$. Two research groups $(24,25)$ showed that transplantation of enzymatically normal congenic bone marrow resulted in increased galactosylceramidase levels in the CNS of the twitcher mouse. Furthermore, globoid cells were gradually replaced by foamy macrophages of donor origin, which were capable of metabolizing the storage product (27). Also, extensive remyelination was observed in the CNS. For BMT to have therapeutic value in twitcher mice, it must be performed within $12 \mathrm{~d}$ after birth. When BMT was performed on d 18, there was no beneficial effect; in fact, the animals died earlier than without BMT (27). Thus, twitcher mice and humans with infantile-onset disease have a narrow window for initiating a successful treatment using BMT.

An alternative therapeutic approach is to compensate for the reduced level of galactosylceramidase by restricting the synthesis of the substrates galactosylceramide and psychosine, thereby alleviating the burden of degradation (28-30). Substrate-reduction therapy has been proposed to treat storage diseases for many years $(28,29,31)$, and there has been success using the glycosphingolipid synthase inhibitor $\mathrm{N}$ butyldeoxynojirimycin to alleviate the clinical signs in animal models of Tay-Sach and Sandhoff diseases (glucosphingolipid lysosomal storage diseases) $(32,33)$ and in humans with Gaucher disease (34). L-Cycloserine is an inhibitor of 3-ketodyhydrosphingosine synthase, which catalyzes an early step in the biosynthetic pathway for the synthesis of psychosine and cerebrosides including galactosylceramide (35). Subcutaneous injections of L-cycloserine lowered the levels of sphingolipids including ceramide and sphingomyelin in the brains of normal mice $(36,37)$, and galactosylceramide levels were reduced in myelin (38). When L-cycloserine was administered to twitcher mice, it prolonged the life-span and slowed the progression of clinical and pathologic signs (39). Substrate-reduction therapy is anticipated to have therapeutic value in adult- and juvenileonset GCL, in which low to moderate levels of residual enzyme activity still may be present. Thus, a reduction of substrate synthesis would enable the residual degradation capacity of galactosylceramidase to keep up with the lowered accumulation of substrates. In the infantile-onset variants, sub- strate-reduction therapy might be able to slow the disease progression and increase life expectancy, but it would not be expected to totally arrest the disease process (33). The limiting factor is the availability of sufficient residual enzyme activity to catabolize the reduced substrate levels entering the lysosome. A complete shutdown of galactosylceramide synthesis is not advisable as this can result in its own disease (40). Thus, the goal of substrate-reduction therapy is to achieve a balance of substrate reduction to a point where residual enzyme activity can manage the substrate burden while not reducing the level of substrate to the point where its deficiency compromises normal physiologic processes. These considerations suggest that a reduction in substrate synthesis may be useful as a supplementary treatment to other therapies for restoring function such as BMT or gene therapy. In a recent study, the combined approach of substrate-reduction therapy, using $\mathrm{N}$ butyldeoxynojirimycin, plus BMT resulted in an improved disease course in mice with Sandhoff disease (41), which is a neuronal storage disease caused by the failure to digest $\mathrm{G}_{\mathrm{M} 2}$ ganglioside. An objective of the present study was to treat twitcher mice, which fail to digest psychosine and galactosylceramide, with both BMT and L-cycloserine to see whether life expectancy can be enhanced beyond that for either therapy alone. A second objective was to evaluate whether initial treatment with L-cycloserine can allow for a delayed BMT to have therapeutic value in twitcher mice.

\section{METHODS}

Breeder mice heterozygous for the twitcher mutation (C57BL/6J,twi/+) (Jackson Laboratories, Bar Harbor, ME, U.S.A.) were maintained under standard housing conditions in a pathogen-free environment with free access to food and water. Animal handling protocols were in accordance with institutional guidelines for animal care and use. This study was approved by the Animal Care and Use Committee of the University of Kansas Medical Center.

The genetic status for the twitcher mutation was determined by PCR on DNA extracted from clipped tails of 5- to 6-d-old pups according to the method of Sakai et al. (20), except that a touch down PCR protocol was used.

All chemicals were purchased from Sigma Chemical Company (St. Louis, MO, U.S.A.), except HBSS, which was purchased from Mediatech (Herndon, VA, U.S.A.). Busulfan was dissolved in a few drops of acetone and suspended in $1 \%$ carboxymethylcellulose. L-Cycloserine was dissolved in sterile PBS before each use. Polymyxin B and neomycin sulfate were dissolved in distilled water.

Bone marrow transplantation. The transplantation procedure was based on the study by Yeager et al. (26), which has been shown to result in successful engraftment (42). Briefly, cohorts of twitcher mice and control littermates were injected with busulfan, $40 \mathrm{mg} / \mathrm{kg}$ body weight i.p., at d 8 or 9 after birth, followed by BMT $24 \mathrm{~h}$ later with $\mathrm{C} 57 \mathrm{BL} / 6$ donor cells. Wild-type C57BL/6 donor mice with normal galactosylceramidase activity were killed by lethal halothane narcosis. The bone marrow was flushed from the tibia and femora with a 22-gauge needle into $15-20 \mathrm{~mL}$ of HBSS on ice. A single-cell suspen- 
sion of bone marrow cells was prepared by repetitive gentle pipetting with a sterile Pasteur pipette. The procedure was performed in a hood with stringent aseptic conditions. Aliquots of bone marrow cells were diluted $(1: 100)$, and total numbers of viable cells were counted on a hemocytometer by the trypan blue exclusion method. Cells were then washed twice with ice-cold HBSS with centrifugation at $400 \mathrm{rpm}$ and finally resuspended in HBSS.

Cells were kept on ice until injection, which was usually within 30 min of collection. Each mouse was given a dose of $50 \pm 5 \times 10^{6}$ viable bone marrow cells by i.p. injection with a tuberculin syringe and 29-gauge needle. For $6 \mathrm{wk}$ after BMT, mice were provided with prophylactic neomycin (final concentration, $500 \mu \mathrm{g} / \mathrm{mL}$ ) and polymyxin B (final concentration, 13 $\mu \mathrm{g} / \mathrm{mL}$ ) added to the drinking water. A few food pellets were put on the bedding to facilitate feeding.

Substrate reduction and early BMT (postnatal d 9-10). Four groups of twitcher mice were used for experiment 1, which analyzed the effects of L-cycloserine on the clinical course of twitcher mice given early BMT: group 1, no treatment; group 2, PBS + BMT; group 3, L-cycloserine (from d 3-4) + BMT; and group 4, L-cycloserine (from d 30) + BMT. The experimental design and injection regimens are described in Table 1.

Substrate reduction and delayed BMT (d 18 or 25). Four groups of twitcher mice were used for experiment 2, which analyzed the effects of L-cycloserine on the clinical course of twitcher mice given late BMT: group 1, only BMT at d 18, group 2, only L-cycloserine; group 3, L-cycloserine + BMT at $\mathrm{d} 18$; and group 4, L-cycloserine + BMT at d 25. The experimental design and injection regimens are described in Table 2.

Survival and body weight. Transplanted mice in each group were observed on a daily basis for signs of infection or transplantation-related complications. Body weight was recorded on the ninth or 10th postnatal day and thereafter every 10th day throughout their lives as an objective measure for development and progression of the disease. When a mouse reached a moribund condition, characterized by the animal's

Table 1. Substrate reduction + early BMT in twitcher mice

\begin{tabular}{|c|c|c|c|c|}
\hline Group & Injection dose & Postnatal days of injection & BMT & $\begin{array}{l}\text { Number } \\
\text { of mice }\end{array}$ \\
\hline 1 & - & - & - & 7 \\
\hline 2 & $\begin{array}{c}\text { vehicle (PBS), } \\
\text { s.c., on } \\
\text { alternate } \\
\text { days }\end{array}$ & d 3 or $4-$ until moribund & d 9 or 10 & 9 \\
\hline 3 & $\begin{array}{l}\text { L-cycloserine, } \\
\text { s.c., on } \\
\text { alternate } \\
\text { days }\end{array}$ & & d 9 or 10 & 6 \\
\hline \multirow{6}{*}{4} & $50 \mathrm{mg} / \mathrm{kg}$ & d 3 or $4-$ d 29 or 30 & & \\
\hline & $35 \mathrm{mg} / \mathrm{kg}$ & d 31 or $32-$ d 49 or 50 & & \\
\hline & $25 \mathrm{mg} / \mathrm{kg}$ & $\begin{array}{l}\text { d } 51 \text { or } 52-\text { until } \\
\text { moribund }\end{array}$ & & \\
\hline & $\begin{array}{l}\text { L-cycloserine, } \\
\text { s.c., on } \\
\text { alternate } \\
\text { days }\end{array}$ & & d 9 or 10 & 8 \\
\hline & $35 \mathrm{mg} / \mathrm{kg}$ & d $30-50$ & & \\
\hline & $25 \mathrm{mg} \mathrm{kg}$ & d 52-until moribund & & \\
\hline
\end{tabular}

Table 2. Substrate reduction + delayed BMT in twitcher mice

\begin{tabular}{|c|c|c|c|c|}
\hline Group & Injection dose & Postnatal days of injection & BMT & $\begin{array}{l}\text { Number } \\
\text { of mice }\end{array}$ \\
\hline 1 & no L-cycloserine & - & d 18 & 9 \\
\hline 2 & $\begin{array}{l}\text { L-cycloserine } 50 \\
\mathrm{mg} / \mathrm{kg} \text {, s.c., } \\
\text { on alternate } \\
\text { days }\end{array}$ & $\mathrm{d} 3$ or $4-\mathrm{d} 29$ or 30 & - & 6 \\
\hline 3 & $\begin{array}{l}\text { L-cycloserine } 50 \\
\mathrm{mg} / \mathrm{kg} \text {, s.c., } \\
\text { on alternate } \\
\text { days }\end{array}$ & $\mathrm{d} 3$ or $4-\mathrm{d} 29$ or 30 & d 18 & 6 \\
\hline 4 & $\begin{array}{l}\text { L-cycloserine } 50 \\
\mathrm{mg} / \mathrm{kg} \text {, s.c., } \\
\text { on alternate } \\
\text { days }\end{array}$ & $\mathrm{d} 3$ or $4-\mathrm{d} 29$ or 30 & d 25 & 8 \\
\hline
\end{tabular}

incapability of voluntary movement and severe wasting, it was killed by halothane inhalation, and the hindbrain and cervical spinal cord were immersion fixed in buffered formalin.

Neuropathology. Neuropathologic examinations were performed on the hindbrain and cervical spinal cord from transplanted control mice, untransplanted twitcher mice, and twitcher mice that were transplanted on d 9 or 10 and treated with PBS or L-cycloserine. Paraffin sections $(8 \mu \mathrm{m})$ were processed for Griffonia simplicifolia lectin I, MBP, and GFAP staining as previously described (42). G. simplicifolia lectin I has been used to label globoid cells and infiltrating macrophages in the CNS of twitcher mice (43), but it fails to stain resting microglia. Large lectin-positive cells $(>15 \mu \mathrm{m}$ diameter) were considered to be globoid cells and counted in the pons. MBP immunohistochemistry was used to detect demyelination, and GFAP staining was used to measure the extent of astrocytosis.

Statistics. The log rank test was used for comparison of life-span between untransplanted and transplanted twitcher mice and also among transplanted twitcher mice treated with PBS and transplanted twitcher mice treated with early or late L-cycloserine. This test was also used to compare life-span of twitcher mice receiving only L-cycloserine or only delayed BMT with twitcher mice receiving both L-cycloserine and a delayed BMT at 18 or $25 \mathrm{~d}$.

\section{RESULTS}

\section{Survival after early BMT + PBS or L-cycloserine}

Untreated twitcher mice had mean life-span of $37.0 \pm 0.5 \mathrm{~d}$ ( $n=7$; Fig. 1). BMT performed within $10 \mathrm{~d}$ after birth significantly increased the mean life-span to $50.7 \pm 1.6 \mathrm{~d}(p=$ $0.0001, n=9$ ). When BMT was performed either in combination with early L-cycloserine treatment (postnatal d 3-4 until death), or in combination with late L-cycloserine treatment (postnatal d 30 until death), the mean life-span was further increased to $112.2 \pm 18.0 \mathrm{~d}(p=0.0005, n=6)$ and $112.8 \pm$ $20.7 \mathrm{~d}(p=0.0006, n=8)$, respectively, compared with BMT alone. An earlier study showed that twitcher mice treated with only L-cycloserine had a mean life-span of $56.0 \pm 0.8 \mathrm{~d}$ (39).

\section{Body weight after early BMT + PBS or L-cycloserine}

The body weights of untreated twitcher mice, or transplanted twitcher mice treated with PBS or L-cycloserine were similar at 


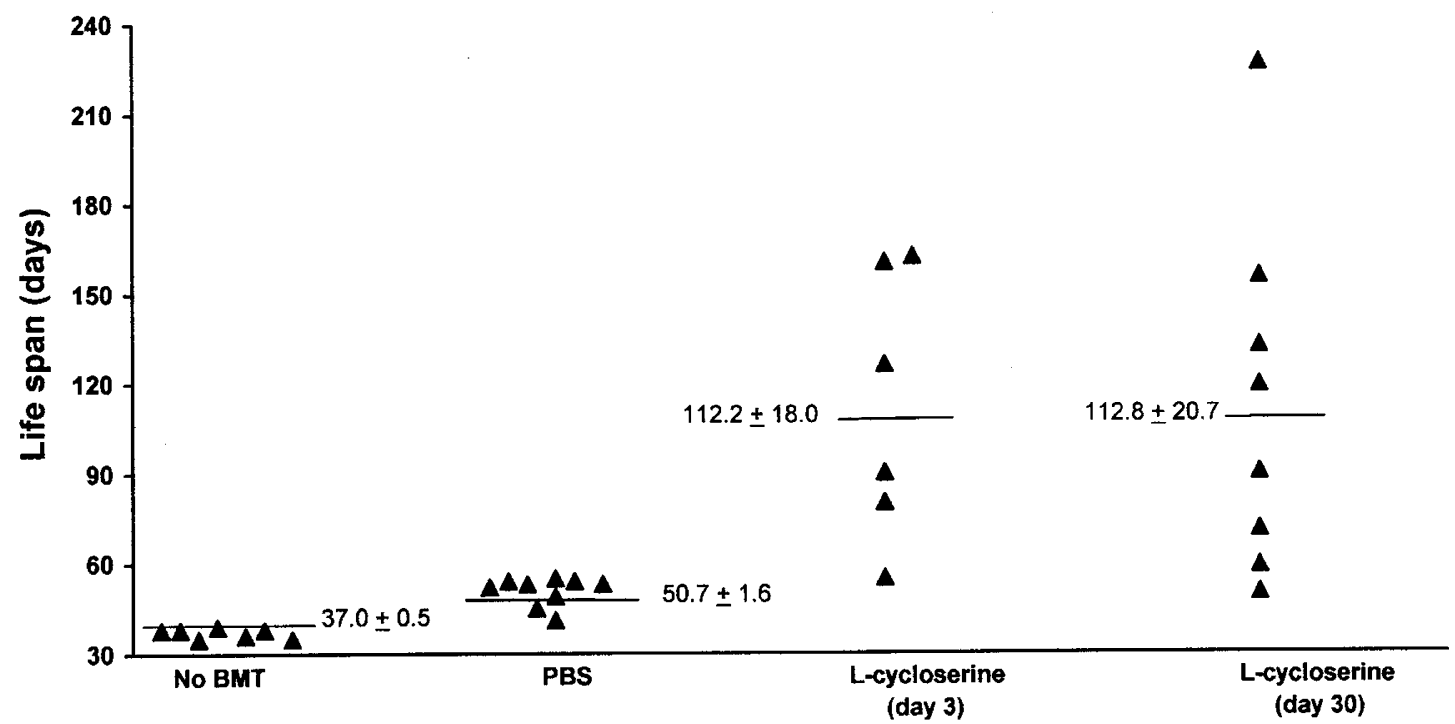

Figure 1. Survival of twitcher mice after BMT + PBS or L-cycloserine. The survival range and mean survival time of twitcher mice given no transplantation $(n=7)$, BMT + PBS $(n=9)$, BMT + L-cycloserine from postnatal d $3(n=6)$, or BMT + L-cycloserine from postnatal d $30(n=8)$ are shown. BMT was performed on postnatal d 9 or 10. BMT + early L-cycloserine- or late L-cycloserine-treated twitcher mice had a significantly longer life-span compared with twitcher mice given BMT + PBS ( $p=0.0005$ and $p=0.0006$, respectively).

10 and $20 \mathrm{~d}$ of age (Fig. 2). Untreated twitcher mice lost weight after $30 \mathrm{~d}$ of age until death, whereas the transplanted twitcher mice typically gained weight beyond $30 \mathrm{~d}$ up until a few days before reaching a moribund condition, when they started to lose weight. Twitcher mice treated with BMT + early

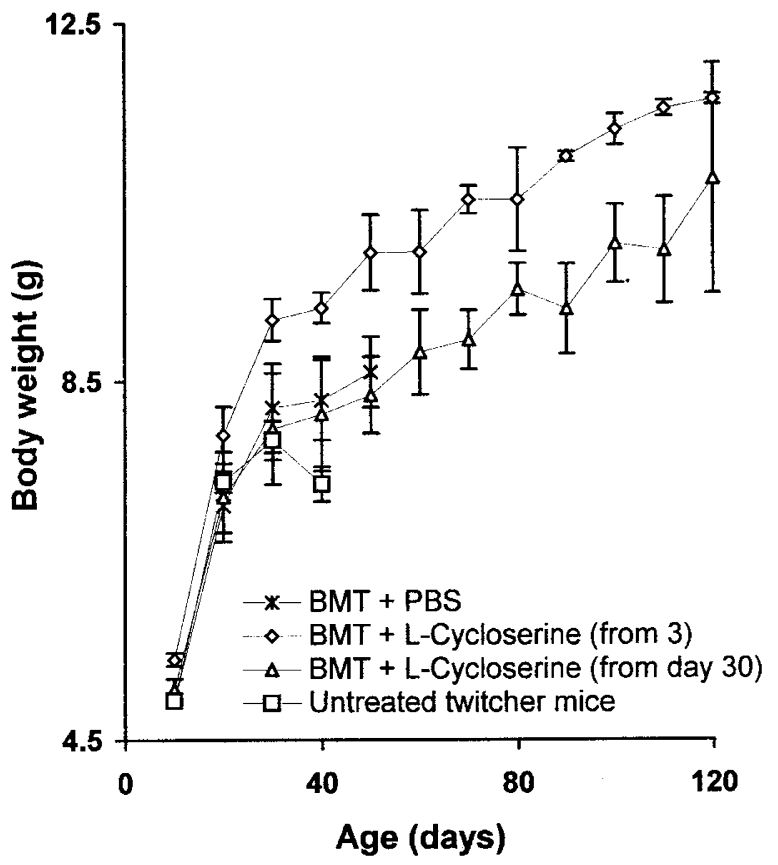

Figure 2. Body weights of twitcher mice after BMT + PBS or L-cycloserine. Absolute body weights of untreated twitcher mice and twitcher mice given $\mathrm{BMT}+$ PBS or L-cycloserine from postnatal d 3 or 30 are shown. Untreated twitcher mice $(n=7)$ lost weight from d 30 until death, whereas most of the transplanted mice treated with PBS $(n=9)$ had a moderate gain in weight throughout their life-span until a few days before becoming moribund. The early L-cycloserine-treated group $(n=6)$ had a greater rate of weight gain compared with the late L-cycloserine-treated group $(n=8)$.
L-cycloserine had a higher body weight by 4 wk of age compared with BMT alone. Twitcher mice with BMT + late L-cycloserine treatment had body weights similar to mice given BMT alone through d 50, and thereafter they gained weight. On average, transplanted mice given early L-cycloserine treatment had a greater body weight throughout their lives compared with transplanted twitcher mice given late L-cycloserine treatment, although the differences did not reach statistical significance.

\section{Neuropathology}

Lectin staining. At $7 \mathrm{wk}$ of age the number of G. simplicifolia-positive globoid cells $(\geq 15 \mu \mathrm{m})$ in transplanted twitcher mice given PBS was less than that for untransplanted twitcher mice at 5 wk (Fig. 3, $C$ versus $B$ ). In transplanted twitcher mice treated either early or late with L-cycloserine, the number of lectin-positive globoid cells in the hindbrain decreased progressively with age (Fig. 3, $D-F$ ). In the hindbrains of mice that were $>100 \mathrm{~d}$ of age, only four to five globoid cells per section were observed together with lightly stained small lectin-positive cells (Fig. $3 E$ ), whereas globoid cells were completely absent in the hindbrain of a 226-d-old transplanted twitcher mouse (Fig. 3F).

GFAP staining. In control mice with or without BMT or L-cycloserine there were only a few stained astrocytes with fine processes (Fig. 4A). Numerous GFAP-stained astrocytes with swollen processes were observed in the hindbrain of untransplanted twitcher mice (Fig. 4B). Gliosis in the hindbrain was less in 7-wk-old, transplanted twitcher mice given PBS (Fig. $4 C)$ compared with 5-wk-old, untransplanted twitcher mice. At 90 and $168 \mathrm{~d}$, gliosis in transplanted twitcher mice treated with L-cycloserine was less than that in untransplanted twitcher mice at $5 \mathrm{wk}$ of age, although the number of labeled astrocytes remained high (Fig. 4, $D$ and $E$ versus $B$ ). In one transplanted 


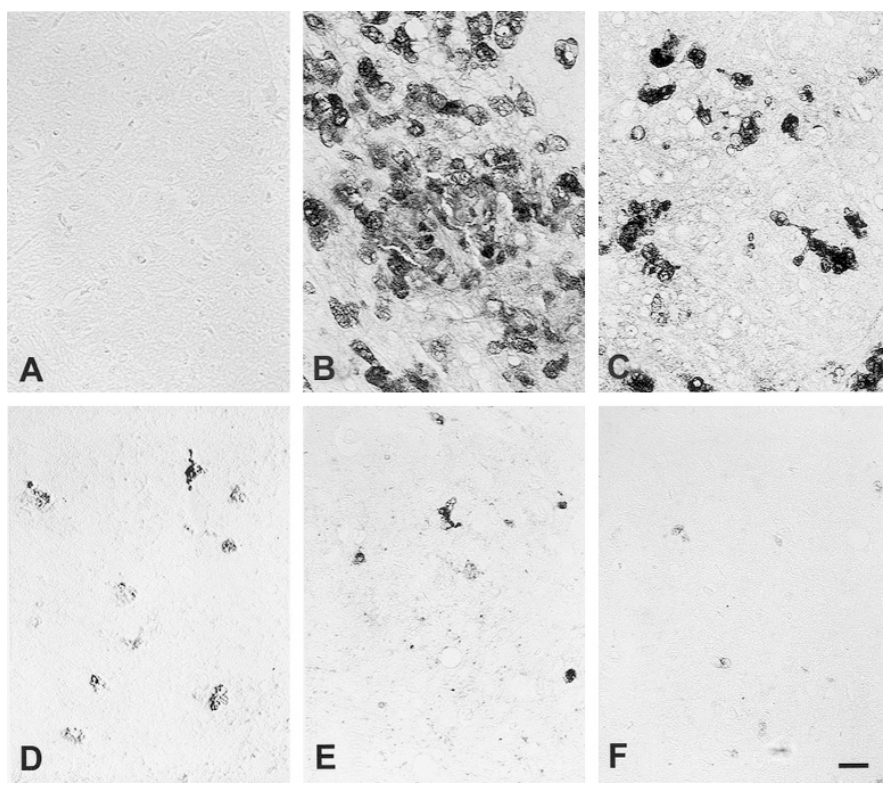

Figure 3. Lectin staining after BMT + PBS or L-cycloserine. Lectin staining in the pons of transplanted control mice $(A)$, untreated twitcher mice $(B)$, and transplanted twitcher mice with PBS $(C)$ or L-cycloserine treatment $(D-F)$ is shown. Transplanted control mice had no lectin staining. Untransplanted twitcher mice had numerous lectin-positive globoid cells $(\geq 15 \mu \mathrm{m})$ at $5 \mathrm{wk}$ of age. After BMT + PBS at 7 wk of age in twitcher mice, the number of globoid cells was less than that for untransplanted twitcher mice. Lectin-positive cells decreased progressively with age $(90,126$, and 226 d) in BMT + Lcycloserine-treated twitcher mice $(D, E, F$, respectively). Bar $=20 \mu \mathrm{m}$.

twitcher mouse treated with L-cycloserine that died at $226 \mathrm{~d}$ (Fig. 4F), there was markedly less GFAP staining in the hindbrain compared with similarly treated twitcher mice dying at an earlier age.

MBP immunohistochemistry. The extent of demyelination was similar at $7 \mathrm{wk}$ of age in transplanted twitcher mice treated with PBS compared with 5-wk-old untransplanted twitcher mice (Fig. 5, $C$ versus $B$ ). In transplanted twitcher mice treated with L-cycloserine, demyelination was still readily apparent (Fig. 5, $D$ and $E$ ) despite a decrease in globoid cell number. A very low level of MBP staining also was found in the cerebellum of a 226-d-old twitcher mice (Fig. 5F) even though it had a 6-fold increase in life-span compared with untransplanted twitcher mice.

\section{Survival after delayed BMT with or without L-cycloserine}

Twitcher mice given BMT alone at $\mathrm{d} 18$ had a mean life-span of $35.8 \pm 1.2 \mathrm{~d}$ ( $n=9$; Fig. 6$)$, which was similar to the life-span of untransplanted mice $(37.0 \pm 0.5 \mathrm{~d}, n=7$; Fig. 1). A short course of L-cycloserine from d 3 to 30 also had no effect on the mean life-span of twitcher mice $(37.6 \pm 1.6 \mathrm{~d}$, $n=6)$. However, a short course of L-cycloserine + BMT at $\mathrm{d}$ 18 significantly prolonged the life-span to $57.5 \pm 2.3 \mathrm{~d}(n=6)$ compared with BMT alone ( $p=0.0004)$ or $\mathrm{L}$-cycloserine alone $(p=0.0008)$. L-Cycloserine + BMT performed at d 25 increased the mean life-span to $41.0 \pm 1.6 \mathrm{~d}(n=8)$, which was still significantly higher than BMT alone $(p=0.03)$.

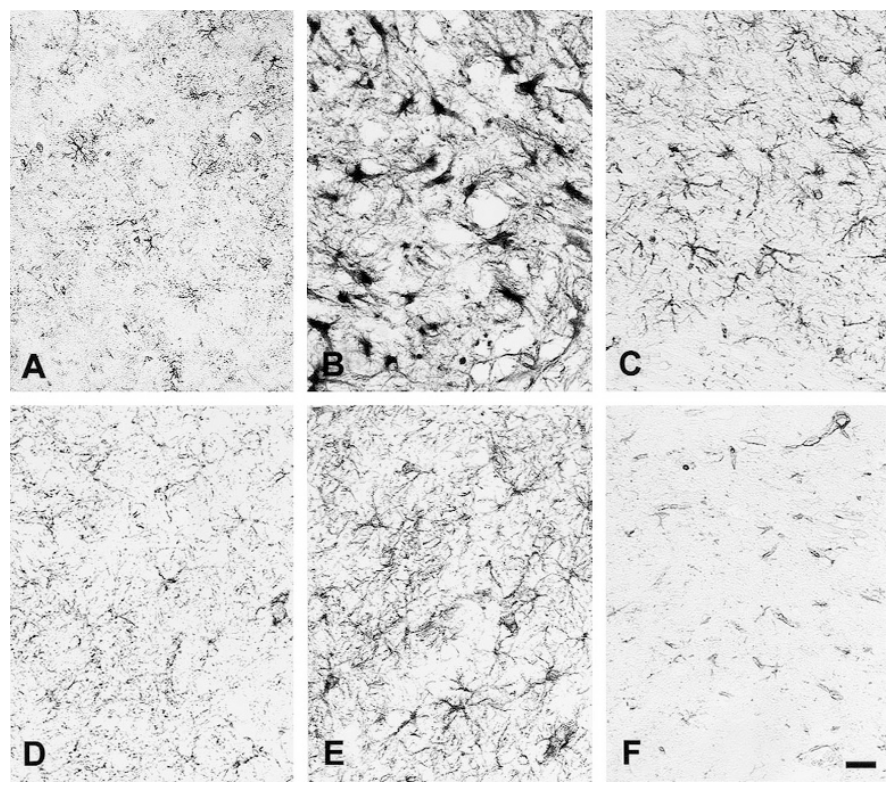

Figure 4. GFAP staining after BMT + PBS or L-cycloserine. GFAP staining in the pons of transplanted control mice $(A)$, untransplanted twitcher mice $(B)$, and transplanted twitcher mice with PBS $(C)$ or L-cycloserine treatment $(D-F)$ is shown. Transplanted control mice had a few lightly stained astrocytes in the pons. Untransplanted twitcher mice had severe astrocytosis at $5 \mathrm{wk}$ of age. After BMT + PBS, at $7 \mathrm{wk}$ of age in twitcher mice, the extent of gliosis was less than that for untransplanted twitcher mice. Transplanted twitcher mice with L-cycloserine at 90 and $168 \mathrm{~d}$ ( $D$ and $E$, respectively) had less gliosis than untransplanted twitcher mice. Gliosis was least severe in a 226-d-old twitcher mouse given BMT + L-cycloserine $(F)$. Bar $=20 \mu \mathrm{m}$.

\section{DISCUSSION}

Substrate-reduction therapy $(39,44)$ and enzyme replacement via BMT $(25,42,45,46)$ have been used to successfully extend the life-span of twitcher mice. However, these treatments are limited in their ability to alter the disease course with the majority of treated mice dying before $100 \mathrm{~d}$. In the present study, we explored the possibility that substrate-reduction therapy could be used as a supplemental therapy together with BMT to increase the life expectancy beyond that for either treatment alone. The results from the present study indicate that this combined approach had the desired effect by increasing the survival beyond that for the individual treatments, which is similar to the findings for substrate-reduction therapy + BMT for Sandhoff disease in mice (41). In twitcher mice, this effect was observed if L-cycloserine was started on d 3-4 or on d 30 in combination with an early BMT. In an earlier study that treated twitcher mice only with L-cycloserine, the beneficial effects were observed when treatment was started at postnatal d 4-5 but not for treatment started at postnatal d 21-22 (39). The explanation for this time constraint was that the galactosylceramide that was scheduled to be recycled already had been synthesized before the initiation of the late administration of L-cycloserine as the turnover rate of myelin is slow (47-49). Thus, in the present study, BMT slowed the disease enough to permit a late regimen of L-cycloserine to contribute to the beneficial effects of the combination therapy. Thus, in patients with GCL in whom transplantation was unable to halt the progression of disease, there is the possibility 

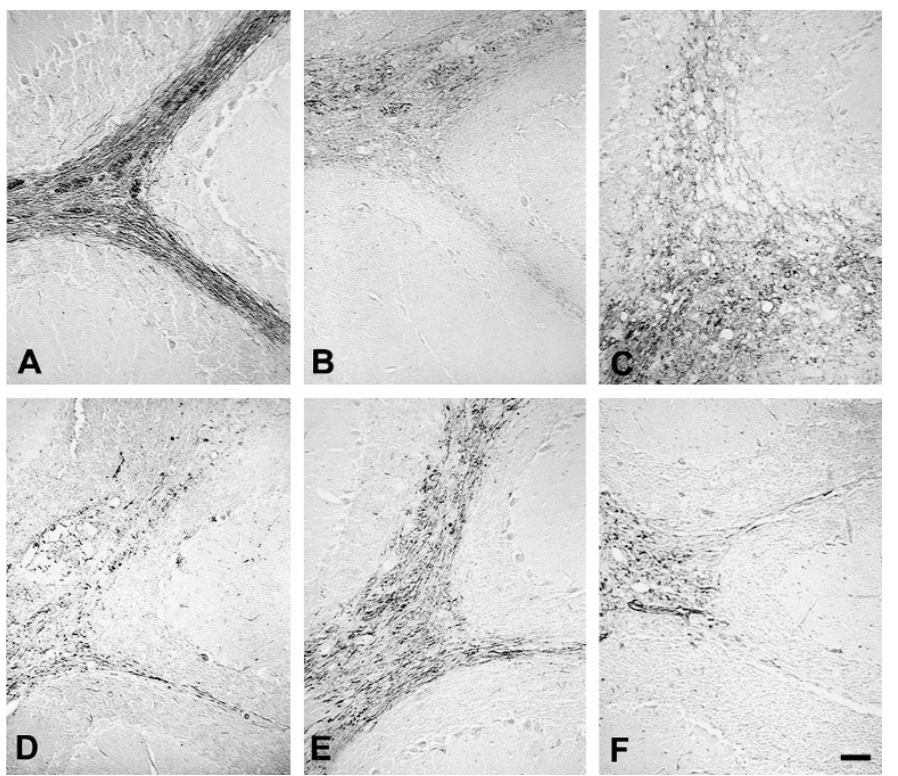

Figure 5. MBP staining after BMT $+\mathrm{PBS}$ or L-cycloserine. MBP staining in the cerebellum of transplanted control mice $(A)$, untransplanted twitcher mice $(B)$, and transplanted twitcher mice with PBS $(C)$ or L-cycloserine treatment $(D-F)$ is shown. Transplanted control mice had normal levels of myelin $(A)$. Untransplanted twitcher mice had severe demyelination at $5 \mathrm{wk}$ of age. After BMT + PBS at $7 \mathrm{wk}$ of age in twitcher mice, demyelination was similar to that for untransplanted twitcher mice. Demyelination was severe regardless of the advanced age $(90,126$, and $226 \mathrm{~d})$ of transplanted twitcher mice receiving L-cycloserine $(D, E$, and $F$, respectively). Bar $=20 \mu \mathrm{m}$.

that they may benefit from the addition of substrate-reduction therapy protocols.

One mouse given this combination therapy lived to $226 \mathrm{~d}$, which is the longest surviving twitcher mouse from the published literature. Pathologically, there was a very low level of
MBP staining in the hindbrain and spinal cord, indicating extensive demyelination. There also was a complete absence of globoid cells and a low level of astrocytosis, which are in contrast to observations of untransplanted twitcher mice or twitcher mice given BMT + L-cycloserine that died at or before $90 \mathrm{~d}$. This result suggests that the globoid cells leave the CNS and that the swelling of reactive astrocytes becomes reduced in long-surviving animals (50). There was an intermediate level of globoid cells in animals that lived between $90 \mathrm{~d}$ and this longest surviving mouse.

BMT has been used to successfully treat patients with late-onset GCL and patients with early onset disease who had an early diagnosis owing to an affected sibling $(12,51,52)$. This therapy has met with much less success for patients with early onset disease who had a diagnosis after several months of life and then underwent transplantation. Twitcher mice, which are thought to be a model of the early onset form of disease, only respond to BMT when it is performed before $\mathrm{d} 12$, which is before the onset of twitching signs. Furthermore, transplanted twitcher mice die before untransplanted twitcher mice if BMT is performed on 18 (27). The second objective of this study was to determine whether early L-cycloserine treatment could slow the disease course to allow for a delayed BMT to have a beneficial effect. When L-cycloserine was started from $\mathrm{d}$ $3-4$, there was a significant increase in the life-span of twitcher mice transplanted at either 18 or $25 \mathrm{~d}$. The dose and duration of L-cycloserine treatment was deliberately selected so that it would not increase the life expectancy by itself. These results suggest that substrate-reduction therapy in combination with BMT may have value for some early onset patients who normally would not respond to BMT alone.

The doses of L-cycloserine used in this study did result in a slightly slower weight gain during the course of treatment for

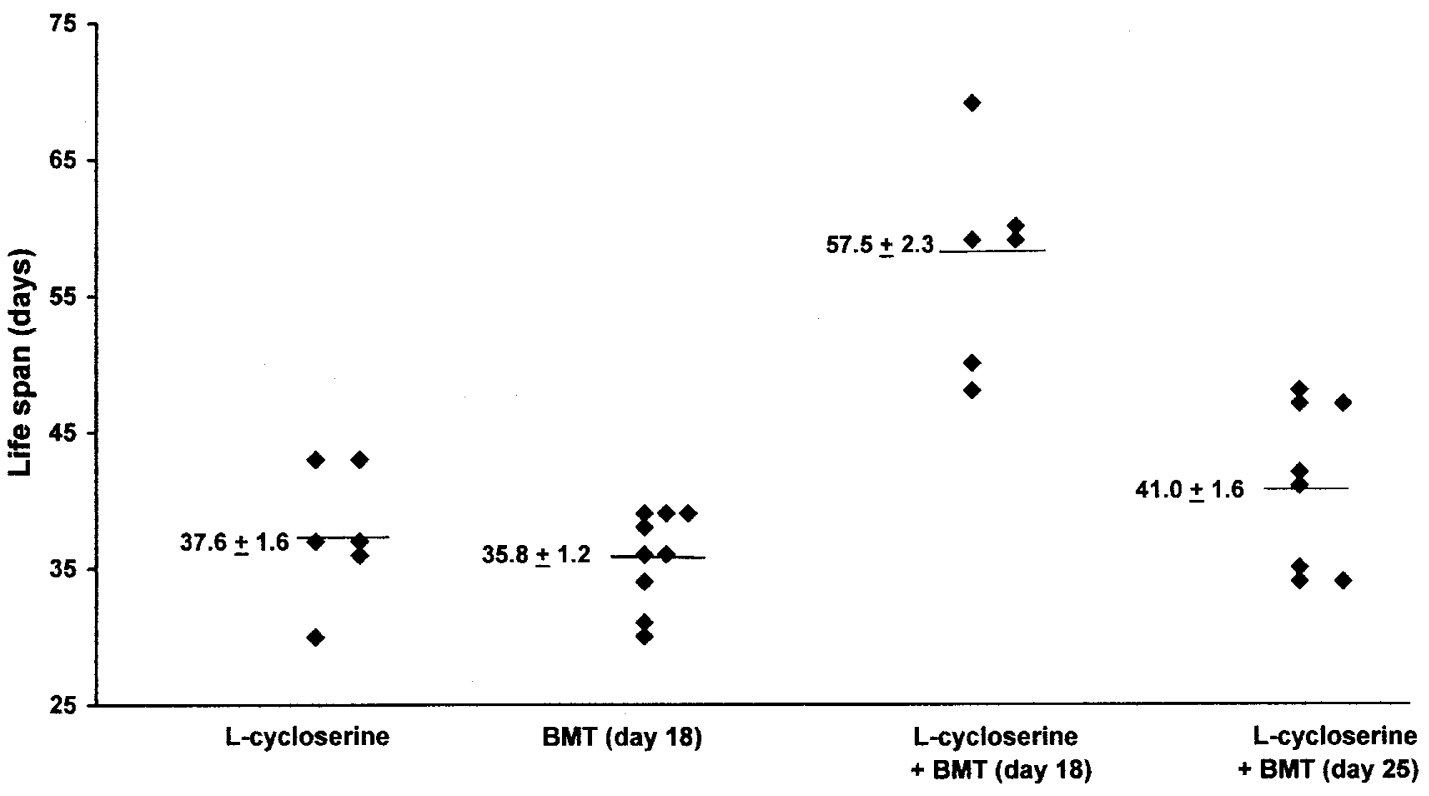

Figure 6. Survival of twitcher mice after delayed BMT + L-cycloserine. Survival range and mean life-span of twitcher mice with only L-cycloserine treatment from postnatal d 3-30 $(n=6)$, only BMT at d $18(n=9)$, or L-cycloserine + BMT at postnatal d 18 or $25(n=6$ and $n=8$, respectively) are shown. L-Cycloserine + delayed BMT (at d 18) significantly increased the life-span of twitcher mice compared with either BMT at d 18 ( $p=0.0004)$ or L-cycloserine alone $(p=0.0008)$. L-Cycloserine + BMT at d 25 also significantly increased the life-span compared with BMT alone $(p=0.03)$. 
littermate control mice (data not shown). Similar doses to the ones used in this study, however, did not result in any abnormal findings on routine pathologic examinations in control mice (39). Because L-cycloserine inhibits the synthesis of sphingosine, it is important to select a treatment regimen that does not completely inhibit the production of sphingosine as it is a key component of cells. Thus, mice did not tolerate doses of L-cycloserine that were much higher than those used in the present study (39).

In summary, substrate-reduction therapy may be a useful strategy to enhance the therapeutic value of BMT and gene therapy protocols for the treatment of GCL and other lysosomal storage diseases.

Acknowledgments. The authors thank Illya G. Bronshteyn for technical assistance in managing the twitcher mouse colony and for performing lectin immunohistochemistry, Julie Collins for MBP and GFAP immunohistochemical staining, Dr. Michael Moser and Niaman Nazir for help with statistical analysis, and Davin Watne, MRRC Imaging Center, for photograph layouts. The authors also thank Dr. David M. Pinson and Dr. Bruce Kimler for their helpful suggestions. The contents of this project and report are solely the responsibility of the authors and do not necessarily represent the official view of the Hunter's Hope Foundation.

\section{REFERENCES}

1. Chen YQ, Rafi MA, de Gala G, Wenger DA 1993 Cloning and expression of cDNA encoding human galactocerebrosidase, the enzyme deficient in globoid cell leukodystrophy. Hum Mol Genet 2:1841-1845

2. Miyataki T, Suzuki K 1972 Globoid cell leukodystrophy: additional deficiency of psychosine galactosidase. Biochem Biophys Res Commun 48:538-543

3. Igisu H, Hamasaki N, Ito A, Ou W 1988 Inhibition of cytochrome $c$ oxidase and hemolysis caused by lysosphingolipids. Lipids 23:345-348

4. Vartanian T, Dawson G, Soliven B, Nelson DJ, Szuchet S 1989 Phosphorylation of myelin basic protein in intact oligodendrocytes: inhibition by galactosylsphingosine and cyclic AMP. Glia 2:370-379

5. Tapasi S, Padma P, Setty OH 1998 Effect of psychosine on mitochondrial function. Indian J Biochem Biophys 35:161-165

6. Svennerholm L, Dreborg S, Erikson A, Groth CG, Hillborg PO, Hakansson G, Nilsson O, Tibblin E 1982 Gaucher disease of the Norrbottnian type (type III). Phenotypic manifestations. Prog Clin Biol Res 95:67-94

7. Bullard W, Southard E 1906 Diffuse gliosis of the cerebral white matter in a child. J Nerv Ment Dis 33:188-193

8. Krabbe K 1916 A new familial, infantile form of diffuse brain sclerosis. Brain $39: 74-114$

9. Wenger DA, Rafi MA, Luzi P, Datto J, Costantino-Ceccarini E 2000 Krabbe disease: genetic aspects and progress toward therapy. Mol Genet Metab 70:1-9

10. Wenger DA 1997 Krabbe Disease (Globoid Cell Leukodystrophy). ButterworthHeinemann, Boston, pp 421-431

11. De Gasperi R, Gama Sosa MA, Sartorato E, Battistini S, Raghavan S, Kolodny EH 1999 Molecular basis of late-life globoid cell leukodystrophy. Hum Mutat 14:256262

12. Krivit W, Shapiro EG, Peters C, Wagner JE, Cornu G, Kurtzberg J, Wenger DA, Kolodny EH, Vanier MT, Loes DJ, Dusenbery K, Lockman LA 1998 Hematopoietic stem-cell transplantation in globoid-cell leukodystrophy. N Engl J Med 338:11191126

13. Krivit W, Lockman LA, Watkins PA, Hirsch J, Shapiro EG 1995 The future for treatment by bone marrow transplantation for adrenoleukodystrophy, metachromatic leukodystrophy, globoid cell leukodystrophy and Hurler syndrome. J Inherit Metab Dis $18: 398-412$

14. Shapiro EG, Lockman LA, Balthazor M, Krivit W 1995 Neuropsychological outcomes of several storage diseases with and without bone marrow transplantation. J Inherit Metab Dis 18:413-429

15. Fu L, Inui K, Nishigaki T, Tatsumi N, Tsukamoto H, Kokubu C, Muramatsu T, Okada S 1999 Molecular heterogeneity of Krabbe disease. J Inherit Metab Dis 22:155-162

16. Kolodny EH, Raghavan S, Krivit W 1991 Late-onset Krabbe disease (globoid cell leukodystrophy): clinical and biochemical features of 15 cases. Dev Neurosci 13:232239

17. Unger ER, Sung JH, Manivel JC, Chenggis ML, Blazar BR, Krivit W 1993 Male donor-derived cells in the brains of female sex-mismatched bone marrow transplant recipients: a Y-chromosome specific in situ hybridization study. J Neuropathol Exp Neurol 52:460-470

18. Wu YP, McMahon E, Kraine MR, Tisch R, Meyers A, Frelinger J, Matsushima GK, Suzuki K 2000 Distribution and characterization of GFP(+) donor hematogenous cells in Twitcher mice after bone marrow transplantation. Am J Pathol 156:18491854

19. Peters C, Krivit W 1997 The Effector Cell of the Central Nervous System following Bone Marrow Transplantation for the Storage Disease. COGENT Press, London, pp $12-23$

20. Sakai N, Inui K, Tatsumi N, Fukushima H, Nishigaki T, Taniike M, Nishimoto J, Tsukamoto H, Yanagihara I, Ozono K, Okada S 1996 Molecular cloning and expression of cDNA for murine galactocerebrosidase and mutation analysis of the twitcher mouse, a model of Krabbe's disease. J Neurochem 66:1118-1124

21. Duchen LW, Eicher EM, Jacobs JM, Scaravilli F, Teixeira F 1980 Hereditary leucodystrophy in the mouse: the new mutant twitcher. Brain 103:695-710

22. Kobayashi S, Katayama M, Satoh J, Suzuki K 1988 The twitcher mouse: an alteration of the unmyelinated fibers in the PNS. Am J Pathol 131:308-319

23. Suzuki K 1995 The twitcher mouse: a model for Krabbe disease and for experimental therapies. Brain Pathol 5:249-258

24. Ichioka T, Kishimoto Y, Brennan S, Santos GW, Yeager AM 1987 Hematopoietic cell transplantation in murine globoid cell leukodystrophy (the twitcher mouse): effects on levels of galactosylceramidase, psychosine, and galactocerebrosides. Proc Natl Acad Sci USA 84:4259-4263

25. Hoogerbrugge PM, Poorthuis BJ, Romme AE, van de Kamp JJ, Wagemaker G, van Bekkum DW 1988 Effect of bone marrow transplantation on enzyme levels and clinical course in the neurologically affected twitcher mouse. J Clin Invest 81:17901794

26. Yeager AM, Shinn C, Pardoll DM 1991 Lymphoid reconstitution after transplantation of congenic hematopoietic cells in busulfan-treated mice. Blood 78:3312-3316

27. Hoogerbrugge PM, Poorthuis BJHM, Wagemaker G, van Bekkum DW, Suzuki K 1989 Alleviation of neurologic symptoms after bone marrow transplantation in twitcher mice. Transplantation Proc 21:2980-2981

28. Radin NS 1999 Chemotherapy by slowing glucosphingolipid synthesis. Biochem Pharmacol 57:589-595

29. Warren KR, Misra RS, Arora RC, Radin NS 1976 Glycosyltransferases of rat brain that make cerebrosides: substrate specificity, inhibitors, and abnormal products. J Neurochem 26:1063-1072

30. Vunnam RR, Radin NS 1980 Analogs of ceramide that inhibit glucocerebroside synthetase in mouse brain. Chem Phys Lipids 26:265-278

31. Radin NS 2000 Treating glucosphingolipid disorders by chemotherapy: use of approved drugs and over-the-counter remedies. J Inherit Metab Dis 23:767-777

32. Jeyakumar M, Butters TD, Cortina-Borja M, Hunnam V, Proia RL, Perry VH, Dwek RA, Platt FM 1999 Delayed symptom onset and increased life expectancy in Sandhoff disease mice treated with $N$-butyldeoxynojirimycin. Proc Natl Acad Sci USA 96:6388-6393

33. Platt FM, Butters TD 1998 New therapeutic prospects for the glycosphingolipid lysosomal storage diseases. Biochem Pharmacol 56:421-430

34. Cox T, Lachmann R, Hollak C, Aerts J, van Weely S, Hrebicek M, Platt F, Butters T, Dwek R, Moyses C, Gow I, Elstein D, Zimran A 2000 Novel oral treatment of Gaucher's disease with $N$-butyldeoxynojirimycin (OGT 918) to decrease substrate biosynthesis. Lancet 355:1481-1485

35. Sundaram KS, Lev M 1985 Inhibition of cerebroside synthesis in the brains of mice treated with L-cycloserine. J Lipid Res 26:473-477

36. Sundaram KS, Lev M 1984 Inhibition of sphingolipid synthesis by cycloserine in vitro and in vivo. J Neurochem 42:577-581

37. Sundaram KS, Lev M 1989 The long-term administration of L-cycloserine to mice: specific reduction of cerebroside level. Neurochem Res 14:245-248

38. Miller SL, Denisova L 1998 Cycloserine-induced decrease of cerebroside in myelin. Lipids 33:441-443

39. LeVine SM, Pedchenko TV, Bronshteyn IG, Pinson DM 2000 L-Cycloserine slows the clinical and pathological course in mice with globoid cell leukodystrophy (twitcher mice). J Neurosci Res 60:231-236

40. Ezoe T, Vanier MT, Oya Y, Popko B, Tohyama J, Matsuda J, Suzuki K 2000 Biochemistry and neuropathology of mice doubly deficient in synthesis and degradation of galactosylceramide. J Neurosci Res 59:170-178

41. Jeyakumar M, Norflus F, Tifft CJ, Cortina-Borja M, Butters TD, Proia RL, Perry VH, Dwek RA, Platt FM 2001 Enhanced survival in Sandhoff disease mice receiving a combination of substrate deprivation therapy and bone marrow transplantation. Blood 97:327-329

42. Biswas S, Pinson DM, Bronshteyn IG, LeVine SM 2001 IL-6 deficiency allows for enhanced therapeutic value after bone marrow transplantation across a minor histocompatibility barrier in the twitcher (globoid cell leukodystrophy) mouse. J Neurosci Res 65:298-307

43. Taniike M, Suzuki K 1994 Spacio-temporal progression of demyelination in twitcher mouse: with clinico-pathological correlation. Acta Neuropathol 88:228-236

44. Ezoe T, Vanier MT, Oya Y, Popko B, Tohyama J, Matsuda J, Suzuki K 2000 Twitcher mice with only a single active galactosylceramide synthase gene exhibit clearly detectable but therapeutically minor phenotypic improvements. J Neurosci Res 59:179-187

45. Yeager AM, Brennan S, Tiffany C, Moser HW, Santos GW 1984 Prolonged survival and remyelination after hematopoietic cell transplantation in the twitcher mouse. Science 225:1052-1054

46. Yeager AM, Shinohara M, Shinn C 1991 Hematopoietic cell transplantation after administration of high-dose busulfan in murine globoid cell leukodystrophy (the twitcher mouse). Pediatr Res 29:302-305 
47. Smith ME 1968 The turnover of myelin in the adult rat. Biochim Biophys Acta 164:285-293

48. Jungalwala FB, Dawson RM 1971 The turnover of myelin phospholipids in the adult and developing rat brain. Biochem J 123:683-693

49. Jungalwala FB 1974 The turnover of myelin phosphatidylcholine and sphingomyelin in the adult rat brain. Brain Res 78:99-108

50. Suzuki K, Hoogerbrugge PM, Poorthuis BJ, Bekkum DW 1988 The twitcher mouse. Central nervous system pathology after bone marrow transplantation. Lab Invest 58:302-309
51. Krivit W, Aubourg P, Shapiro E, Peters C 1999 Bone marrow transplantation for globoid cell leukodystrophy, adrenoleukodystrophy, metachromatic leukodystrophy, and Hurler syndrome. Curr Opin Hematol 6:377-382

52. Krivit W, Peters C, Shapiro EG 1999 Bone marrow transplantation as effective treatment of central nervous system disease in globoid cell leukodystrophy, metachromatic leukodystrophy, adrenoleukodystrophy, mannosidosis, fucosidosis, aspartylglucosaminuria, Hurler, Maroteaux-Lamy, and Sly syndromes, and Gaucher disease type III. Curr Opin Neurol 12:167-176 